\title{
Erratum to: Characterization of two proline dipeptidases (prolidases) from the hyperthermophilic archaeon Pyrococcus horikoshii
}

\author{
Casey M. Theriot • Sherry R. Tove • Amy M. Grunden
}

Published online: 27 October 2009

(C) Springer-Verlag 2009

\section{Erratum to: Appl Microbiol Biotechnol}

\section{DOI 10.1007/s00253-009-2235-x}

This article unfortunately contained a mistake.

Figure 2 was presented incorrectly. The correct Fig. 2 which shows Phprol (PH1149) and Ph1prol (PH0974) relative activities over $\mathrm{pH}$ range $4-10$ is displayed below.

The online version of the original article can be found at http://dx.doi. org/10.1007/s00253-009-2235-x.

C. M. Theriot $\cdot$ S. R. Tove

Department of Microbiology, North Carolina State University,

4548 Gardner Hall, Campus Box 7615, Raleigh,

NC 27695-7615, USA

\section{A. M. Grunden $(\triangle)$}

Department of Microbiology, North Carolina State University,

4550A Gardner Hall, Campus Box 7615, Raleigh,

NC 27695-7615, USA

e-mail: amy_grunden@ncsu.edu

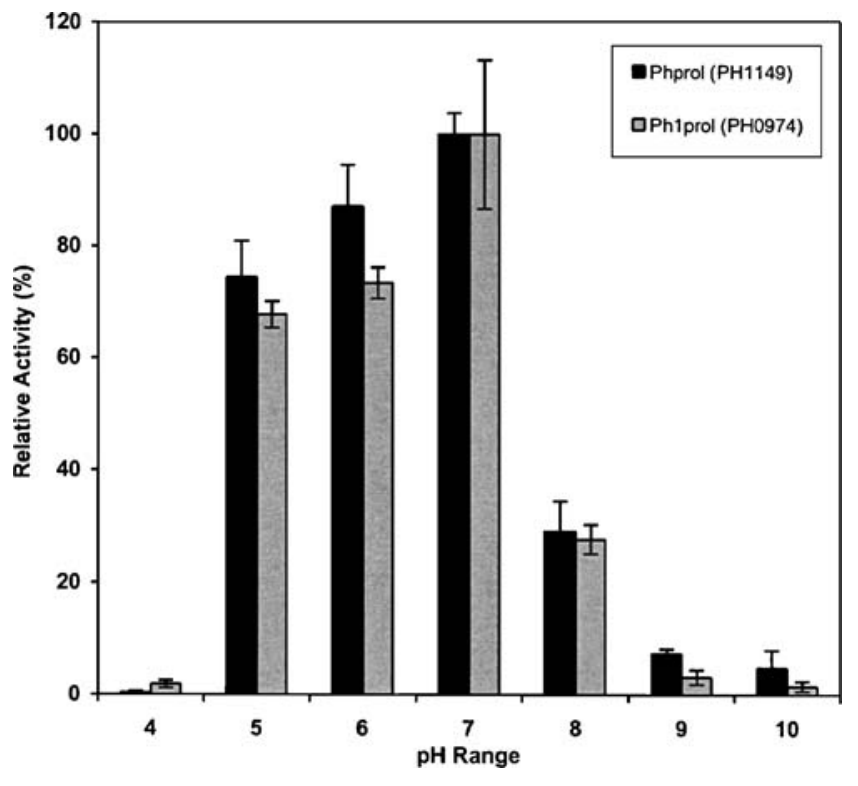

Fig. 2 Activity of $P$. horikoshii prolidases over a pH range of 4.0-10.0. Prolidase assays contained $14.8 \mathrm{ng}$ for Phprol and $6.2 \mathrm{ng} P h 1 \mathrm{prol}$, MetPro $(4 \mathrm{mM})$ and $\mathrm{CoCl} 2(1.2 \mathrm{mM})$. The following buffers were used for each $\mathrm{pH}$ at a final concentration of $100 \mathrm{mM}$ : $\mathrm{pH} 4.0-5.0$, Sodium Acetate; pH6.0-8.0, MOPS; pH9.0, CHES; pH10.0, CAPS. $100 \%$ specific activity corresponds to $2,321 \mathrm{U} / \mathrm{mg}$ for $P h$ prol and 3,357 U/mg for $P h l$ prol 